\title{
Optimization of dynamic reactive power devices' coordinate operation for minimizing HVDC's successive commutation failure based on PSO
}

\author{
Qun Li, Ningyu Zhang *, Xinyao Zhu and Jian Liu \\ State Grid Jiangsu Electric Power CO.LTD Research Institute, Nanjing, China \\ *Corresponding Author: zhangny190@163.com
}

Submitted :21/05/2020

Revised :06/08/2021

Accepted : 24/08/2021

\begin{abstract}
More and more dynamic reactive power devices (DRPDs) have been put into operation to improve voltage stability in AC/DC hybrid power system. In order to make full use of these devices, this paper presented an optimization technology for multiple DRPDs' coordinate operation in the receiving-end of AC/DC hybrid power system. DRPDs' steady-state reactive instructions are treated as optimization variables in the proposed model, while the objective is minimizing the successive times of HVDC's commutation failure under a number of grounding faults. Power flow constraints and electromechanical transient process are considered simultaneously. Based on the characteristics of the model, commutation failure of HVDC under each grounding fault could be obtained by employing time-domain simulation method. Furthermore, particle swarm optimization (PSO) is used to get DRPDs' optimal reactive instruction in steady-state. The simulation is done by considering Jiangsu power grid in eastern China, including synchronous condenser, STATCOM, and UPFC. The results show that the proposed model and algorithm are corrective and effective.
\end{abstract}

Keywords: Dynamic reactive power device; AC/DC hybrid power grid; Commutation failure; Coordinate operation.

\section{INTRODUCTION}

In China, the high-voltage direct current (HVDC) system plays an important role in delivering high-capacity power over long-distance. Compared with voltage source converter (VSC) technology, line-commutated converter (LCC) has the advantages of high capacity, lower cost, and reliable operation. Therefore, LCC technology is preferred in most of the HVDC projects and utilized for large scale renewable energy's transmission in western China.

To improve energy consumption efficiency, HVDC inverter stations have usually access to heavy electrical load center, such as metropolitan regions. These locations are characterized by higher environmental protection requirement and scarce land resource, so that fewer power plants have been allowed to be established, and less 
reactive power is provided. Furthermore, due to switching devices' principle, LCC-HVDC consumes lots of reactive power during transferring real power. Besides that, extra reactive power from AC grid is needed during LCCHVDC's commutation failure process. Such features lead to lower voltage phenomenon and weaker voltage support ability in the receiving-end of AC/DC hybrid power system (Zhang et al., 2016). For example, as the most important component in Jiangsu province, Suzhou power grid has about 50\% external electricity, which contains $\pm 800 \mathrm{kV}$ Jinsu HVDC (720MW) based on LCC and other three 500kV AC transmissions. Due to the heavy electrical load and weak voltage support from local power plants, dynamic voltage stability becomes the most serious issue in Suzhou power grid.

In order to improve voltage stability of AC/DC hybrid power system, building dynamic reactive power devices (DRPDs) have been regarded as effective ways to improve voltage stability (Zhou,S.H. et al., 2018; Zhou,Y.Z. et al., 2018; Zhao et al., 2014; Xiao et al., 2014). Taking China as an example, dozens of synchronous condensers (SCs) are settled near HVDC converter stations in recent years. Beyond that, Wujiang 220kV STATCOM, Nanjing 220kV UPFC, and Suzhou 500kV UPFC have been put into operation successively in China.

While a growing number of DRPDs have created excellent environment for improving voltage stability of AC/DC hybrid grid, how to schedule these devices coordinately becomes critical to stimulate the maximum voltage regulation ability (Zhou et al., 2014). In recent years, researchers have sought some achievements in this field. Chen proposed a novel two-stage dynamic reactive power dispatch method, which effectively realized coordinated dispatch of distributed generations (Chen et al., 2019). Rehman introduced a coordinated control between an UHVDC-HCS system and STATCOM, while using commutation failure immunity index (CFII) and commutation failure probability index (CFPI) to evaluate the robustness of the method (Atiq et al., 2019). Li developed a coordinated multiobjective reactive voltage control system, which could be able to regulate SCs, LV capacitors, and reactors at the same time (Li et al., 2019). Guo pointed out that CFII and fault recovery time are the practical indexes to judge whether LCCHVDC and VSC-HVDC are coordinately operated (Guo et al., 2017). The authors proposed a novel controller to make full use of SCs at inverter side of HVDC, and specific parameters were testified in very weak inverter AC systems (Gragan et al., 2020). Ding introduced a multimode control strategy for the static synchronous compensator and fixed capacitors, and the probability of commutation failure was reduced responsively (Ding et al., 2017). Li designed a kind of emergency control system for SCs to prevent HVDC continuous commutation failure (Li et al., 2018).

Combinate optimal power flow (OPF) or unit commitment (UC) with DRPDs is another effective approach to optimize those operation strategies. The authors introduced OPF framework, in which STATCOM was used to strengthen static voltage profile (Ambarish et al., 2017). The operational paradigms were obtained by Genetic Algorithm (GA), Hybrid Algorithm (HA), and Bacteria Foraging Algorithm (BFA). STATCOM possessed reactive power control capabilities by optimizing operational parameters (Behzad et al., 2014). The above process was realized though the method of incorporating STATCOM model into the OPF formulation using Lagrangian functions. The paper of Sreejith et al. (2015) developed UC model with different FACTS devices. By using Artificial Bee Colony $(\mathrm{ABC})$ algorithm, the reduction of generation cost and elimination of transmission lines' overload were recognized through FACTS devices' regulation. Zora et al. (2019) investigated UC model with FACTS devices and energy storage. By analyzing the characteristics of their joint impact, optimal operation modes were presented. The paper of Li et al. (2018) compared several dispatch strategies of UPFC and provided useful advises on employing UPFC to deal with wind power's uncertainties. In the paper of Taher et al. (2020), UPFC was utilized to regulate the bus voltage though OPF technology. The work proposed a simplified UPFC model into OPF and a physical-based optimization method to solve the whole model.

Nevertheless, existing achievements mainly focus on the coordinated control strategy of multiple DRPDs on device-level. However, the control strategy of DRPD is fixed and not changed easily along with power grid's change. Dispatchers' main commission is deciding the reactive instruction in steady-state of DRPD, because these values 
directly impact the reactive power distribution between the steady and transient operation of DRPD. It further influences the voltage stability of the whole power system. Although some researchers make use of OPF or UC to obtain operation strategies of FACTS devices, they only consider steady-state constraints of power system and ignore the transient characteristic after faults. As a result, it is necessary to optimize the steady-state reactive instruction for each DRPD, so that dynamic voltage stability of power grid could be reinforced both steady and transient operation at the same time. In addition, with more DRPDs emerging in power system, how to operate them coordinately is also critical. Accordingly, the main contributions of this research work are summarized in what follows:

(1) It is the first time to research DRPDs' coordinate operation from the view of power system's dispatching. The objective is to minimize the successive times of HVDC's commutation failure under a number of grounding faults.

(2) PSO method is adopted in combination with (1) to efficiently deal with algebraic equations and differential equations simultaneously.

(3) The model and algorithm in (2) are testified by considering Jiangsu power grid in eastern China, containing multiple DRPDs. It shows that the introduced method could be used to optimize operation of actual AC/DC hybrid power grids.

This paper is organized in six sections as follows. After the introduction section, typical models of several DRPDs are summarized and introduced in Section 2. As the main contribution in this paper, an optimization model for multiple DRPDs' coordinate operation is firstly proposed to improve the voltage stability of AC/DC hybrid power grid in Section 3. PSO algorithm-based solution is presented in Section 4, while it is tested with Jiangsu power grid in eastern China in Section 5. Finally, the conclusion is discussed in Section 6.

\section{DYNAMIC REACTIVE POWER DEVICES}

In this section, several typical DRPD will be introduced, including SC, STATCOM, and UPFC.

\section{Synchronous condenser}

In China, new generation SC have the same technical principle and operation characteristics with the traditional ones (Sha et al., 2019). It is mentioned that the transient response speed and overload capability are extensively improved to meet the requirement of $\mathrm{AC} / \mathrm{DC}$ hybrid power grid. The specific advantages of new generation $\mathrm{SC}$ are shown in the following:

1) More overload capacity. The stator winding of SC can withstand 3.5 times the rated current, while the duration time should not be less than $15 \mathrm{~s}$. Meanwhile, it is also more than $15 s$ the duration of 2.5 times rated excitation current acting on rotor winding. The requirement of step-up transformer is the same as the stator.

2) Faster dynamic response. Smaller subtransient reactance could lead to a large amount of reactive power generated by SC at the moment of the grounding fault. Forced excitation voltage response is much faster so as to increase the excitation current quickly.

The reactive current response of SC in case the terminal voltage suddenly changes could be represented by formula (1). 


$$
i_{d}=\frac{E_{q[0]}-U_{0+}}{X_{d}}+\left(\frac{E_{q 0}^{\prime}-U_{0+}}{X_{d}^{\prime \prime}}-\frac{E_{q 0}^{\prime}-U_{0+}}{X_{d}^{\prime}}\right) e^{-\frac{t}{T_{d}^{\prime \prime}}}+\left(\frac{E_{q 0}^{\prime}-U_{0+}}{X_{d}^{\prime}}-\frac{E_{q[0]}-U_{0+}}{X_{d}}\right) e^{-\frac{t}{T_{d}^{\prime}}}-\frac{U_{0-}-U_{0+}}{X_{d}^{\prime \prime}} e^{-\frac{t}{T_{a}}} \cos \left(w t+\delta_{0}\right)
$$

It can be seen from formula (1) that the magnitude of instantaneous reactive power output after fault is mainly determined by voltage variation amplitude and subtransient reactance. Greater voltage variation and smaller subtransient reactance would lead to more instantaneous reactive power output.

\section{Statcom}

STATCOM is an advanced dynamic VAR compensator to regulate AC voltage of the grid (Zheng et al., 2018). A typical STATCOM is composed by voltage source converter based on IGBT, whose electrical structure and phasor relationship with grid voltage is shown by the following:

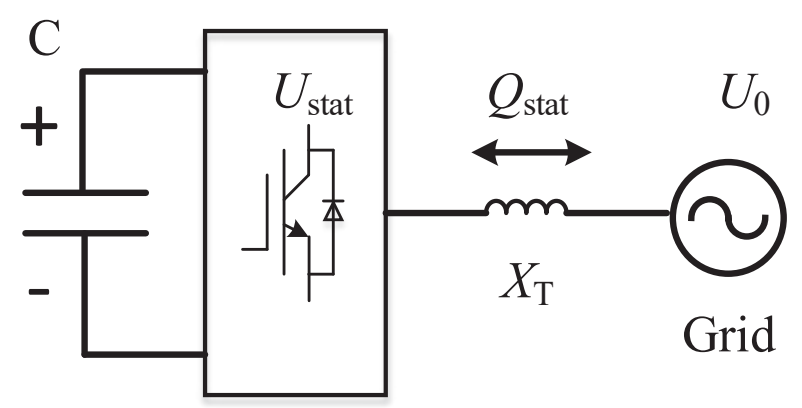

(a) Electrical structure

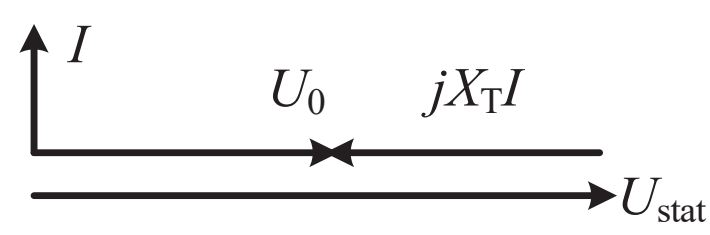

(b) Absorb reactive power

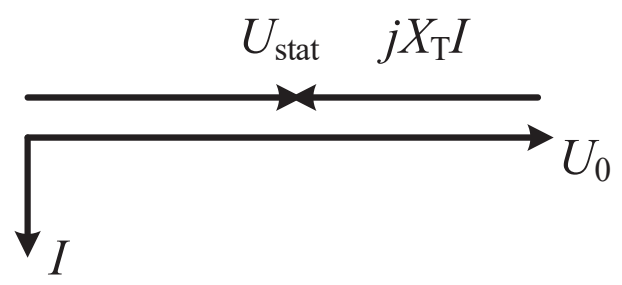

(c) Generate reactive power

Figure 1. Typical electrical structure and voltage phasor diagram of STATCOM. 
The reactive power exchange among STATCOM and power grid could be treated as the charging and discharging process between regulated capacitor and power grid. In the transient process, STATCOM presents the characteristics of voltage source. The control strategy universally utilized in STATCOM is double closed-loop feedback control. The current inner loop has fast response speed and could improve the current to the target value within milliseconds.

\section{UPFC}

Unified power flow controller (UPFC), one of the most powerful FACTS devices, can simultaneously control node voltage, phase angle, and line impedance. It gathers the control characteristics of the devices such as static synchronous compensator, static VAR compensator, phase shifter, controlled series compensation, and short-circuit current limiter.

The parallel inverter could absorb or generate reactive power to AC system, and the control diagram is shown as follows:

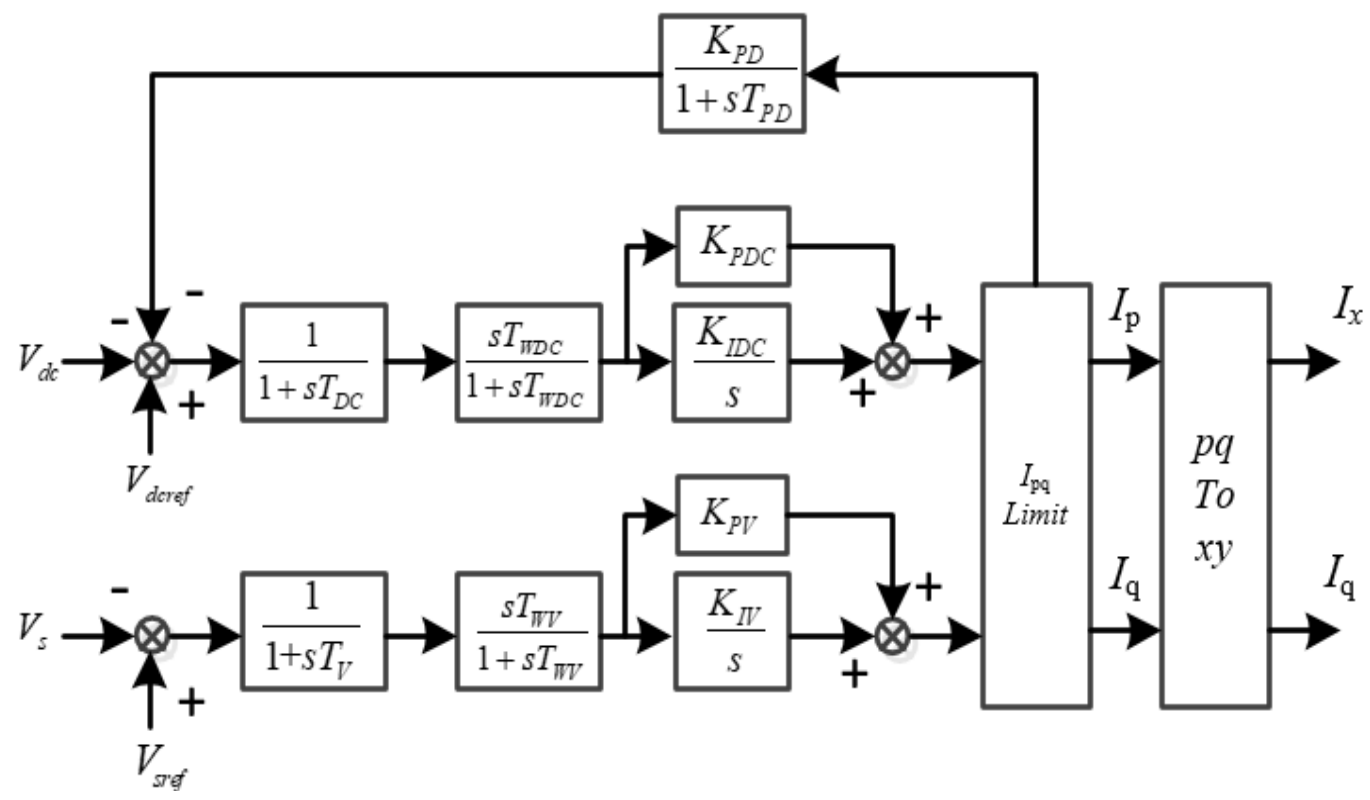

Figure 2. Typical control structure of UPFC's parallel inverter.

\section{OPTIMIZATION MODEL for DRPDs in AC/DC HYBRID GRID}

In this section, an optimization model for DRPDs' coordinate operation is presented from the view of power grid dispatching. Within this model, the main objective is to minimize the average times of HVDC's continuous commutation failure under grounding faults. The optimization variables involve steady-state reactive output of DRPDs, such as SC, STATCOM, and UPFC. The constraints could be divided into two categories: the first is the steady operation constraints, which are used to ensure power balance and nodal voltages within limits; the other is the transient operation constraints, simulating electromechanical process and calculating successive times of HVDC's commutation failure under three phase to ground faults. The whole model is introduced in detail as follows: 


\section{A. Objective Function}

The objective function aims to minimize the average successive times of HVDC's commutation failure. It means that the more suitable the steady-state reactive power of DRPDs, the fewer the objectives.

$$
\min C F_{A V E}=\frac{1}{N_{f}} \sum_{i=1}^{N_{f}} T_{i}
$$

Due to the large number of transmission branches in the power grid, each branch has the possibility of shortcircuit fault. Therefore, considering the average commutation failure times can better reflect the accuracy of the proposed model.

\section{B. Power Flow Constraints}

The reactive power generated from DRPD in the steady-state must satisfy the maximum and minimum operating limits:

$Q_{\min , j} \leq Q_{j}^{S S} \leq Q_{\max , j} \quad j=1,2, \ldots . M$

The active and reactive power balance equations at each bus without HVDC feed-in are shown in (4) and (5).

$0=P_{L, m}+V_{m} \sum_{n \in m} V_{n}\left(G_{m n} \cos \theta_{m n}+B_{m n} \sin \theta_{m n}\right)$
$0=Q_{L, m}+V_{m} \sum_{n \in m} V_{n}\left(G_{m n} \sin \theta_{m n}-B_{m n} \cos \theta_{m n}\right)$

For these buses with HVDC, constraints (6) and (7) are utilized to ensure the power balance.

$0=P_{L, m} \pm \sum_{l \in m} P_{d, l}+V_{m} \sum_{n \in m} V_{n}\left(G_{m n} \cos \theta_{m n}+B_{m n} \sin \theta_{m n}\right)$

$0=Q_{L, m} \pm \sum_{n \in m} Q_{d, l}+V_{m} \sum_{n \in m} V_{n}\left(G_{m n} \sin \theta_{m n}-B_{m n} \cos \theta_{m n}\right)$

Constraint (8) limits voltage amplitude and phase angle with respective range at each node bus.

$V_{m, \min } \leq V_{m} \leq V_{m, \max }, m \in N_{B}$

$-\pi \leq \theta_{m} \leq \pi, m \in N_{B}$

\section{LCC-HVDC Model}

Formulas (10)-(16) show the whole HVDC' quasi-steady state model. The converter equations (10) and (11) express the relationship between $V_{\mathrm{dR}}\left(V_{\mathrm{dI}}\right)$ and $V_{\mathrm{m}}\left(V_{\mathrm{n}}\right), k_{\mathrm{R}}\left(k_{\mathrm{I}}\right), \alpha(\gamma)$ and other converter variables, while the coupling transformers are assumed to be lossless. Formula (12) represents the DC voltage-current relationship, which depends 
on the DC transmission system configuration (i.e., $V_{\mathrm{dR}}, V_{\mathrm{dI}}$ and $I_{\mathrm{d}}$ ). After obtaining the active power of both rectifier and inverter from formulas (13)-(14), the exchange reactive power between AC and DC system could be calculated through formulas (15)-(16) by considering reactive compensation capacity $Q_{\mathrm{Cl}}$ and $Q_{\mathrm{CR}}$.

$$
\begin{aligned}
& V_{d R}=\frac{3 \sqrt{2}}{\pi} n_{R} k_{R} V_{m} \cos \alpha-\frac{3}{\pi} n_{R} X_{c, R} I_{d} \\
& V_{d I}=\frac{3 \sqrt{2}}{\pi} n_{I} k_{I} V_{n} \cos \gamma-\frac{3}{\pi} n_{I} X_{c, I} I_{d} \\
& V_{d R}=V_{d I}+R_{d} I_{d} \\
& P_{d R}=V_{d R} I_{d} \\
& P_{d I}=V_{d I} I_{d} \\
& Q_{d R}=Q_{C R}-\sqrt{\left(V_{d R}+\frac{3}{\pi} n_{R} X_{c R} I_{d}\right)^{2} \frac{I_{d}^{2}}{\cos ^{2} \alpha}-P_{d R}^{2}} \\
& Q_{d I}=Q_{C I}-\sqrt{\left(V_{d I}+\frac{3}{\pi} n_{I} X_{c I} I_{d}\right)^{2} \frac{I_{d}^{2}}{\cos ^{2} \gamma}-P_{d I}^{2}}
\end{aligned}
$$

It is common knowledge that LCC-HVDC should be operated under two different control modes. As reported by the related paper of HVDC projects, constant power mode is used in rectifier station, while constant voltage is preferred to inverter station.

\section{Electromechanical Transient Constraints}

Formulas (17)-(22) constitute the electromechanical transient process of AC/DC hybrid system with DRPDs. They not only contain differential equations of AC power grid (Eq. 17), but also involve quasi-steady state of HVDC (Eq. 18) and the transient simulation of DRPDs (Eq. 19). By employing the time-domain simulation method, the successive times of HVDC's commutation failure under each grounding fault would be calculated, as represented by formula (20).

$$
\begin{aligned}
& 0=\phi_{A C}\left(\dot{X}_{A C}, X_{A C}, Z\right) \\
& 0=\phi_{H V D C}\left(\dot{X}_{H V D C}, X_{H V D C}\right) \\
& 0=\phi_{D R C}\left(\dot{X}_{D R C}, X_{D R C}\right) \\
& T_{i}=F\left(\dot{X}_{A C}, \dot{X}_{H V D C}, \dot{X}_{D R C}, X_{A C}, X_{H V D C}, X_{D R C}, Z, \varphi_{i}\right) i=1,2, \ldots N_{f}
\end{aligned}
$$




\section{MODEL SOLUTION}

Formulas (1)-(20) constitute the whole optimization model, which comprise algebraic equations and differential equations simultaneously. By generalizing the model, the summarized equations are shown as (21)-(23). Formula (21) represents the objective function, including variables such as the output of DRPDs. Formula (22) represents algebraic constraints, containing power flow balance, upper and lower limits of reactive output, voltage constraints, and so on. Equation (23) represents the differential constraints dominated by electromechanical transient simulation equations.

$\min X$

$A X=b$

$F_{d}(X, \dot{Y}, Y)=0$

Due to the existence of electromechanical transient, such conventional optimal algorithms as interior point method (IPO), dynamic programming (DP), and mixed integer programming (MIP) are not suitable any more. For this reason, particle optimization (PSO) could be an appropriate choice to the proposed problem. Because of the mutual learning properties between particles, PSO is one of the heuristic optimization algorithms and has been proved to be robust, of fast convergence, and of high accuracy.

PSO algorithm consists of a population continuously updating the knowledge of the given searching space. This population is formed by individuals denoted as particles; each one represents a possible solution. Unlike evolutionary algorithms, each particle moves in the searching space with a velocity, which is dynamically updated based on its previous velocity. The particle's location where the best fitness has been achieved is denoted as pbest in (24). gbest is that population where pbest is located. The velocity of the $i_{\text {th }}$ element is updated as

$$
\begin{gathered}
V_{i, j}^{i t e r+1}=w V_{i, j}^{i t e r}+C_{1} * \operatorname{rand}() *\left(\text { pbest }-X_{p s o, i}\right)+C_{2} * \operatorname{Rand}() *\left(\text { gbest }_{i}-X_{p s o, i}\right) \\
\text { for } i=1,2, \ldots, N I N D j=1,2, \ldots, N V A R
\end{gathered}
$$

The position of each particle is updated at each iteration; this is done by adding the velocity vector to the position vector, as described in the following:

$$
X_{p s o, i, j}^{i t e r+1}=X_{p s o, i, j}^{i t e r}+V_{i, j}^{i t e r+1}
$$




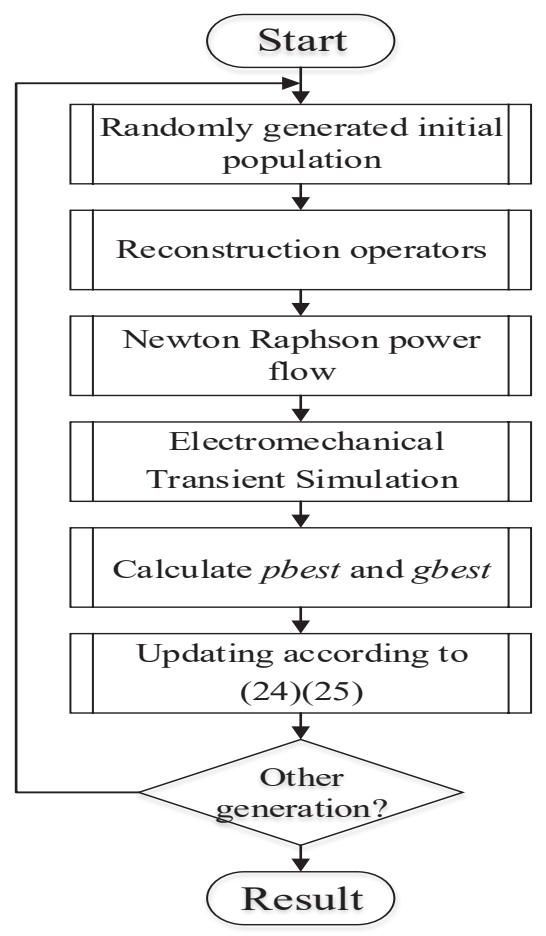

Figure 3. The flowchart of proposed algorithm.

The proposed algorithm flowchart is depicted in Figure 3. The major steps are summarized as follows.

\section{A. Initial Population}

In this paper, a particle is composed by $\mathrm{M}$ continuous control variables, including the reactive output of DRPDs. Within a subpopulation, each particle is defined by a column of size M coinciding with the number of reactive devices. The ith reactive output of $\mathrm{jth}$ particle is initialized as follows:

$Q_{j}^{S S}=\operatorname{rand}()^{*}\left(Q_{\text {max }, j}-Q_{\text {min }, j}\right)+Q_{\min , j}$

\section{B. Power Flow Calculation}

Power flow is a basic calculation to provide steady operation point, which is used to process electromechanical transient simulation of power grid. Among the existing power flow algorithms, Newton-Raphson method has the advantages of converging quickly and low requirement for starting point.

\section{Fitness Function}

The fitness of each particle is the average times of HVDC's continuous commutation failure under $N_{\mathrm{f}}$ phase to ground faults, shown in formula (1). To achieve this calculation, time-domain simulation is selected to analyze transient process of HVDC under each fault. Then, the commutation failure times of HVDC could be obtained through the curve of extinction angle at the inverter station. 


\section{Updating}

The new position (updating within the searching space) can be evaluated by (24) and (25).

In this paper, the weight $w$ in (24) is defined by a linearly decreasing function (27), starting from a relatively large value $\left(w_{\max }=0.9\right)$ and diminishing toward a small one $\left(w_{\min }=0.4\right)$, while the PSO is evolving. This strategy aids the global search at the beginning of the iterative process and the local search at the end of the iterative process.

$$
w=w_{\max }-\frac{w_{\max }-w_{\min }}{\text { iter }_{\max }} * \text { iter }
$$

where iter $_{\text {max }}$ expresses the maximum number of iterations; iter symbolizes the current iteration.

\section{RESULTS AND DISCUSSION}

The proposed methodology has been applied to southern Suzhou power grid in Jiangsu province of China. As one of the most important components in China, Jiangsu's highest dispatching electrical load has exceeded 100 million kilowatts, and three $\pm 800 \mathrm{kV}$ HVDC projections (Jinsu, Yanhuai, and Xitai) have been put into operation at the end of 2019. It also contains 214 thermal generators and $23001000 / 500 / 230 \mathrm{kV}$ transmission lines. It is worth mentioning that Jinsu HVDC is fed into Sunan district, which is the important load center of Jiangsu province. This region grid possesses two remarkable characteristics: 1) motor load proportion already reached 58\%; 2) external power, including Jinsu HVDC and thermal plants, accounted for $52 \%$ electricity load. Those lead to lower dynamic voltage support ability in south Suzhou power grid. For the purpose of improving the voltage stability and ensuring Jinsu HVDC's stable operation, such dynamic reactive devices as SC, STATCOM, and UPFC have been developed progressively in the local power grid. The specific information of these reactive power devices is shown in Figure 4 and Table 1.

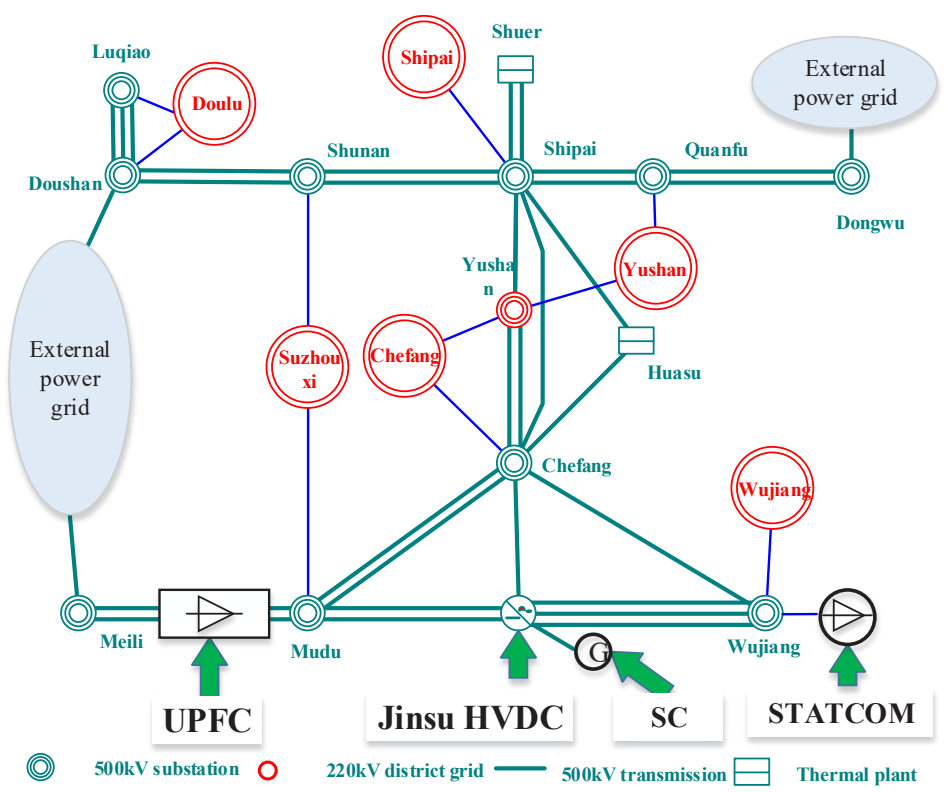

Figure 4. The distribution of DRPDs in Suzhou power grid. 
Table 1. The details of DRPDs in Suzhou power grid.

\begin{tabular}{|c|c|c|c|c|}
\hline No. & Devices & Position & Voltage level & Capacity \\
\hline 1 & SC & Jinsu HVDC & $500 \mathrm{kV}$ & $300 \mathrm{MVA} \times 2$ \\
\hline 2 & STATCOM & Wujiang substion & $220 \mathrm{kV}$ & $300 \mathrm{MVA}$ \\
\hline 3 & UPFC & Meili-Mudu transmission & $500 \mathrm{kV}$ & 250MVA (Shunt converter) \\
\hline
\end{tabular}

The whole PSO algorithm is coded in Matlab 2017a. During the process, power flow calculation is realized by using MatPower 7.0, while electromechanical transient simulation under each three phases to ground fault is proceed by BPA. The program could be called by PSO algorithm and realized in Matlab. In the end, the number of commutations failures would be calculated automatically.

In order to illuminate the correctness of the proposed algorithm, four cases of southern Suzhou power grid have been taken into account. It should be noted that simulation data include Jiangsu power grid and three HVDC transmissions.

Case 1: Southern Suzhou power grid with SCs

Case 2: Southern Suzhou power grid with STATCOM

Case 3: Southern Suzhou power grid with UPFC

Case 4: Southern Suzhou power grid with SCs, STATCOM and UPFC.

Before the numerical tests are carried out, several parameters of the proposed approach must be set. They include swarm size, acceleration coefficients, scaling constant, probability of mutation, and stop criterion. Table 2 lists suitable values of the parameters for the test systems, based on experiments that were performed previously by the authors.

Table 2. The setting parameters of PSO in four cases.

\begin{tabular}{|c|c|c|c|c|}
\hline Parameters & \multicolumn{4}{|c|}{ Southern Suzhou power grid } \\
\hline & Case1 & Case2 & Case3 & Case4 \\
\hline Variable number & 2 & 1 & 1 & 4 \\
\hline Swarm size & 10 & 10 & 10 & 20 \\
\hline Acceleration coefficients & 0.5 & 0.5 & 0.5 & 0.5 \\
\hline Scaling constant & 20 & 20 & 20 & 20 \\
\hline Probability of mutation & 0.1 & 0.1 & 0.1 & 0.1 \\
\hline Stop criterion & 20 & 20 & 20 & 40 \\
\hline N-1 short circuit fault number & 50 & 50 & 50 & 50 \\
\hline
\end{tabular}


The simulation results of the proposed PSO approach for four cases are shown in Table 3, and the convergence curve of case 4 is presented in Figure 5. The optimal reactive power of different devices is presented in Table 4.

Table 3. The details of objective in four test systems.

\begin{tabular}{|c|c|c|c|c|}
\hline Objective & Case1 & Case2 & Case3 & Case4 \\
\hline Average commutation failure times & 1.91 & 2.41 & 2.53 & 1.79 \\
\hline
\end{tabular}

Table 4. The optimal reactive power of DRPDs.

\begin{tabular}{|c|c|c|c|c|}
\hline \multirow{2}{*}{ DRPDs } & \multicolumn{4}{|c|}{ Optimal Reactive Power } \\
\cline { 2 - 5 } & Case1 & Case2 & Case3 & Case4 \\
\hline SC & 50.2 & -- & -- & 103.2 \\
\hline STATCOM & -- & 102.1 & -- & 1.2 \\
\hline UPFC & -- & -- & 75.5 & 51.3 \\
\hline
\end{tabular}

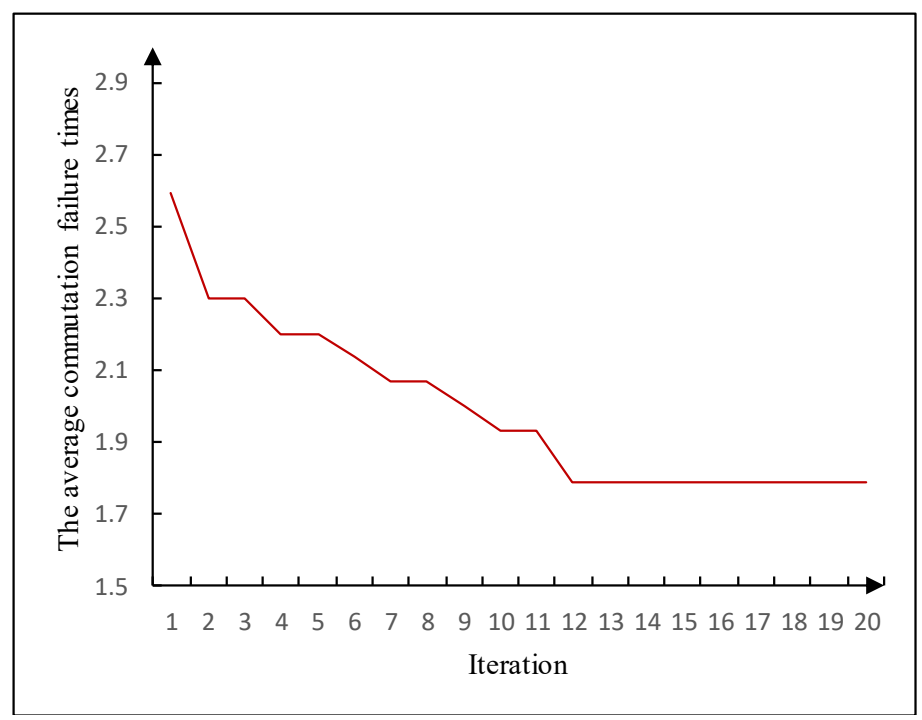

Figure 5. Convergence curve of the PSO approach for the southern Suzhou power grid.

According to all simulation results presented in the tables and figures, the detailed analysis is as follows:

1) Figure 1 displays the convergence curve of the proposed approach for this system. The average commutates failure times as 2.6 at the initiate state. After 13 times iteration, the object decreases to 1.72 , which shows that PSO can efficiently deal with time domain simulation constraints and find the optimal reactive power of several devices. 
2) Among these dynamic reactive power devices, $\mathrm{SC}$ has the best performance on decreasing the successive commutate failure times. The analysis could be processed by the following aspects: (1) Installation position. SCs are located at Suzhou $500 \mathrm{kV}$ bus, which is closer to the inverter station of Jinsu HVDC than STATCOM and UPFC. It means that more reactive power could be supplied from SC to the inverter station after grounding faults and voltage recovery are accelerated correspondingly. (2) Dynamic reactive characteristic. Different with FACTS devices, overload ability of SC during subtransient process leads to more reactive power (about 2-3 times rated capacity) once grounding fault happens so as to improve dynamic voltage procedure of HVDC. Limited by electronic devices' current capacity, UPFC and STATCOM could only provide reactive power up to 1.5 times rated capacity, which are less than SC.

3) Through 12 iterations, the optimal coordinate operation strategy for DRPDs is achieved in case 4. It reduces the average commutation failure times to 1.79 , which is lowest among four cases. Meanwhile, two kinds of accommodation are realized: one is balance between static and dynamic reactive power of each reactive power device. Proper reactive power is provided under steady operation so as to raise voltage, for example, $100 \mathrm{MVar}$ of SCs, $50 \mathrm{MVar}$ of UPFC. At the same time, the remaining reactive power is left for transient process and is used to ramp up voltage recovery when grounding faults happen. The other one is coordination of different reactive power devices. DRPDs at different locations have various effects on HVDC's dynamic characteristic. Hence, the proposed model and algorithm could maximize all DRPDs' voltage regulation ability.

4) Figs. 6 and 7 show the simulation comparison of the optimal result and one arbitrary strategy (SC:0MVar, STATCOM:0MVar, UPFC:0MVar) of DRPDs under one phase or three phases to ground fault in Jiangsu power grid. As shown in Figure 6, because of higher reactive output, AC bus voltage of the inverter station is higher with the optimal strategy. Through further analysis from Figure 7, the optimal strategy could reduce the commutation failure of HVDC to 1, while the commutation failure of HVDC is 2 with the other strategy. The reason is that the optimal DRPDs' strategy realizes rational reactive distribution between steady-state and transient process so as to improve voltage stability greatly.

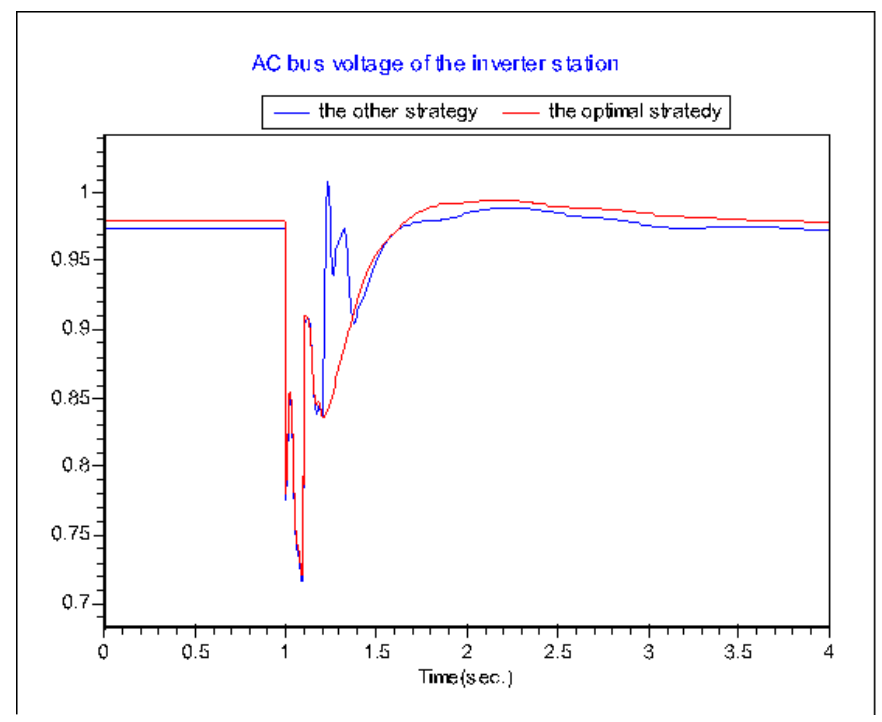

Figure 6. The comparison of the inverter station's AC bus voltage. 


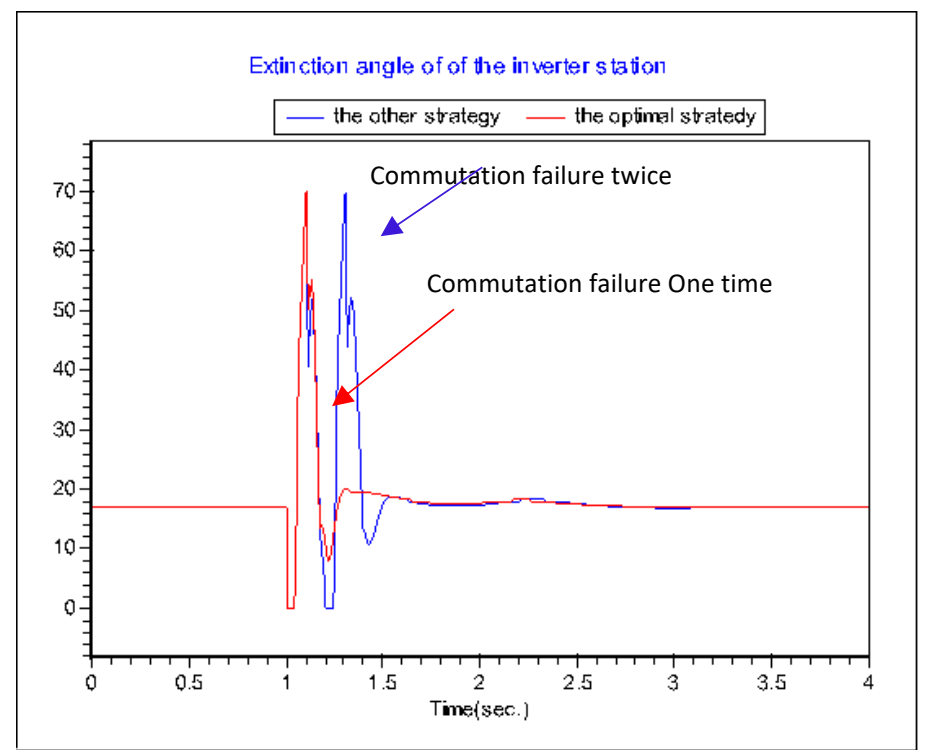

Figure 7. The comparison of the inverter station's extinction angle.

\section{CONCLUSION}

This paper has introduced an optimized model for multiple DRPDs' coordinate operation. Then, the PSO algorithm is employed to solve such a problem with algebra and differential equations. The four cases of southern Suzhou power grid in China were used to demonstrate the effectiveness of model. The proposed approach has been proved reliable by successfully searching the optimal operation strategy for the test systems. The average successive commutation failure of Jinsu HVDC under grounding faults could be reduced effectively by the optimal operation strategy of DRPDs. It is worth noting that, with the continuous operation of HVDC projects in China, the method in this paper has wide applicability. Through the proposed technology, voltage stability could be improved obviously, and DRPDs could be utilized adequately.

NOMENCLATURE

\begin{tabular}{|l|l|l|l|}
\hline \multicolumn{3}{|c|}{ Dynamic reactive power devices } \\
\hline$i_{\mathrm{d}}$ & \multicolumn{1}{|c|}{ The d-axis current of stator } & $X_{\mathrm{d}}$ & \multicolumn{1}{l|}{ The d-axis reactance } \\
\hline$X^{\prime}{ }_{\mathrm{d}}$ & The d-axis transient reactance & $X^{\prime \prime}{ }_{\mathrm{d}}$ & The d-axis sub-transient reactance \\
\hline$E_{\mathrm{q} 0}^{\prime}$ & The transient internal electric potential & $E_{\mathrm{q}[0]}$ & The none-load electric potential \\
\hline$U_{0-}$ & $\begin{array}{l}\text { The terminal voltage before suddenly } \\
\text { change }\end{array}$ & $U_{0+}$ & $\begin{array}{l}\text { The terminal voltage after suddenly } \\
\text { change }\end{array}$ \\
\hline
\end{tabular}




\begin{tabular}{|c|c|c|c|}
\hline$T^{\prime}{ }_{d}$ & $\begin{array}{l}\text { the transient short circuit time constant of } \\
\text { d-axis }\end{array}$ & $T^{\prime \prime} \mathrm{d}$ & $\begin{array}{l}\text { The sub-transient short circuit time } \\
\text { constant of d-axis }\end{array}$ \\
\hline$T_{\mathrm{a}}$ & $\begin{array}{l}\text { The transient time constant of the stator } \\
\text { winding }\end{array}$ & $\omega$ & The synchronous angular velocity \\
\hline$\delta_{0}$ & The phase before short circuit & $U_{0}$ & The voltage of power grid \\
\hline$U_{\text {stat }}$ & AC side voltage of STATCOM & $X_{\mathrm{T}}$ & $\begin{array}{l}\text { Equivalent reactance of step-up } \\
\text { transformer }\end{array}$ \\
\hline$I$ & $\begin{array}{l}\text { Current between STATCOM and power } \\
\text { grid }\end{array}$ & $Q_{\text {stat }}$ & $\begin{array}{l}\text { Reactive power between STATCOM and } \\
\text { AC power grid }\end{array}$ \\
\hline C & Regulated capacitor of DC side & $V_{\text {sref }}$ & The reference voltage of AC bus \\
\hline$V_{\text {dcref }}$ & The reference voltages of DC bus & $T_{\mathrm{DC}}$ & Filter time constant of DC voltage \\
\hline$T_{\mathrm{WDC}}$ & $\begin{array}{l}\text { Time constant of DC voltage branch } \\
\text { isolation }\end{array}$ & $K_{\mathrm{PDC},} K_{\mathrm{IDC}}$ & $\begin{array}{l}\text { Proportional and integral coefficients of } \\
\text { DC voltage }\end{array}$ \\
\hline$T_{\mathrm{V}}$ & Filter time constant of $\mathrm{AC}$ voltage & $T_{\mathrm{WV}}$ & $\begin{array}{l}\text { Time constant of } \mathrm{AC} \text { voltage branch } \\
\text { isolation }\end{array}$ \\
\hline$K_{\mathrm{PV}}, K_{\mathrm{IV}}$ & $\begin{array}{l}\text { Proportional and integral coefficients of } \\
\text { AC voltage }\end{array}$ & $V_{\mathrm{dc}}$ & The voltage of DC bus \\
\hline$V_{\mathrm{s}}$ & The voltage of $\mathrm{AC}$ bus & $I_{\mathrm{p}}, I_{\mathrm{q}}$ & The current of $\mathrm{p}$ - and q-axis \\
\hline$I_{\mathrm{x}}, I_{\mathrm{y}}$ & The current of $\mathrm{x}$ - and $\mathrm{y}$-axis & $N_{B}$ & Number of buses \\
\hline \multicolumn{4}{|c|}{ The optimization model } \\
\hline$C F_{\mathrm{AVE}}$ & The objective of model & $T_{\mathrm{i}}$ & $\begin{array}{l}\text { The successive times of HVDC's } \\
\text { commutation failure under } i_{\text {th }} \text { fault. }\end{array}$ \\
\hline$N_{\mathrm{f}}$ & The number of three phase to ground fault & $\begin{array}{l}Q_{\max , \mathrm{j}} \\
Q_{\mathrm{min}, \mathrm{j}}\end{array}$ & $\begin{array}{l}\text { Maximum and minimum reactive power } \\
\text { limits of } j_{\text {th }} \text { DRPD }\end{array}$ \\
\hline$Q_{\mathrm{j}}^{\mathrm{ss}}$ & $\begin{array}{l}\text { The reactive power output of } j \text { th DRPD at } \\
\text { steady-state }\end{array}$ & $m, n$ & Index of AC bus \\
\hline $\begin{array}{l}P_{\mathrm{L}, \mathrm{m}} \\
Q_{L, m}\end{array}$ & Real and reactive load of bus $m$ & $\theta_{\mathrm{mn}}$ & Phase difference between bus $m$ and $n$ \\
\hline$G_{\mathrm{mn},}, B_{\mathrm{mn}}$ & Admittance between bus $m$ and $n$ & $V_{\mathrm{m}}, V_{\mathrm{n}}$ & Voltage of AC bus $m / n$ \\
\hline$P_{\mathrm{d}, \mathrm{l},}, Q_{\mathrm{dl}}$ & Real and reactive power of DC $l$ & $V_{\mathrm{dR}}, V_{\mathrm{dI}}$ & DC voltage of rectifier / inverter \\
\hline
\end{tabular}




\begin{tabular}{|c|c|c|c|}
\hline \multicolumn{4}{|c|}{ HVDC } \\
\hline$I_{\mathrm{d}}$ & DC current & $\gamma$ & Extinguishing angle \\
\hline$k_{\mathrm{R},}, k_{\mathrm{I}}$ & Transformer tap ratio of rectifier/inverter & $\alpha$ & Trigger delay angle \\
\hline$X_{\mathrm{c}, \mathrm{R},} X_{\mathrm{c}, \mathrm{I}}$ & Leakage reactance of rectifier/inverter & $n_{R}, n_{I}$ & Bridge number of rectifier/inverter \\
\hline$R_{\mathrm{d}}$ & Resistance of HVDC line & $P_{\mathrm{dR}}, P_{\mathrm{dI}}$ & Real power of rectifier/inverter \\
\hline $\begin{array}{l}Q_{\mathrm{dR}} \\
Q_{\mathrm{dI}}\end{array}$ & $\begin{array}{l}\text { Exchange reactive power between } \\
\text { rectifier/ inverter substation and AC grid }\end{array}$ & $Q_{\mathrm{CR}}, Q_{\mathrm{CI}}$ & $\begin{array}{l}\text { Reactive power compensation of } \\
\text { rectifier/inverter substation }\end{array}$ \\
\hline$\varphi_{\mathrm{AC}}$ & Differential equations of $\mathrm{AC}$ power grid & $\varphi_{\mathrm{HVDC}}$ & $\begin{array}{l}\text { Differential equations of HVDC power } \\
\text { grid }\end{array}$ \\
\hline$\varphi \mathrm{DRPD}$ & Differential equations of DRPD & $\begin{array}{l}X_{\mathrm{AC}} \\
X_{H V D C} \\
X_{D R P D}\end{array}$ & The state variables of AC/HVDC/DRPD \\
\hline$Z$ & The control variable of AC system & $F$ & $\begin{array}{l}\text { The calculation of HVDCs' commutation } \\
\text { failure times }\end{array}$ \\
\hline$X$ & The optimal variables & $A, b$ & The parameters of algebraic equations \\
\hline$Y$ & The state variables & $F_{\mathrm{d}}$ & The differential equations \\
\hline \multicolumn{4}{|c|}{ PSO } \\
\hline iter & Index of iteration & $C_{1} 、 C_{2}$ & Positive learning factors \\
\hline$X_{p s o, \mathrm{i}}$ & The actual position of the $i_{\text {th }}$ particle & NIND & The number of particles \\
\hline NVAR & The number of variables & $w$ & The inertia weight \\
\hline$V_{\text {iter,ij }}$ & The velocity of the $i_{\text {th }}$ element & itermax & Maximum number of iterations \\
\hline $\begin{array}{l}w_{\max }, w_{m i} \\
n\end{array}$ & $\begin{array}{l}\text { Maximum and minimum reactive power } \\
\text { limits of inertia weight. }\end{array}$ & & \\
\hline
\end{tabular}




\section{ACKNOWLEDGMENT}

This work is supported by Special support of Jiangsu Province"333 High level Talents Training Project” (No. BRA2020084) and the State Grid Jiangsu Electric Power Co., LTD. Project of "Research on key technologies of flexible interconnection and coordinated operation of multi power flow control devices for urban power grid.’(No.J2021171)

\section{REFERENCES}

Ambarish, P., Tripathy, M. \& Barisal, A.K. 2017. A modified bacterium foraging based optimal power flow framework for Hydro-Thermal-Wind generation system in the presence of STATCOM. Energy 124: 720740.

Atiq, U.R., Guo, C.Y. \& Zhao, C.Y. 2019. Coordinated Control for Operating Characteristics Improvement of UHVDC Transmission Systems under Hierarchical Connection Scheme with STATCOM. Energies 12(5):945-960.

Behzad, K. \& Enrique, A. 2014. An Advanced STATCOM Model for Optimal Power Flows Using Newton's Method. IEEE Transactions on power systems 29(2): 514-525.

Chen, L.J., Deng, Z.L. \& Xu, X.H. 2019. Two-Stage Dynamic Reactive Power Dispatch Strategy in Distribution Network Considering the Reactive Power Regulation of Distributed Generations. IEEE Transactions on Power Systems 34(2):1021-1032.

Ding, L.G., Shen, Y.W. \& Xu, J.Z. 2017. Coordinated Control Strategy of Reactive Compensation for HVDC Converter Station Connected to Weak AC System. Automation of Electric Power Systems 41(8): 22-28.

Dragan, J., Nalin, P. \& Mohamed, Z. 2000. Investigation of the Use of Inverter Control Strategy Instead of Synchronous Condensers at Inverter Terminal of an HVDC System. IEEE Trans on Power Delivery 15(2):704-709.

Guo, C.Y., Yang, Z.Z \& Ning, L.R. 2017. A Novel Coordinated Control Approach for Commutation Failure Mitigation in Hybrid Parallel-HVDC System with MMC-HVDC and LCC-HVDC. Electric Power Components and Systems 45(16): 1773-1782.

Li, J., Liu, F. \& Li, Z.Y. 2018. Impacts and benefits of UPFC to wind power integration in unit commitment. Renewable Energy 116: 570-583.

Li, K., Shao, D.J. \& Xu, Y.P. 2019. Research on Coordinated Multi-objective Reactive Voltage Control System Based on New Type Synchronous Condenser. Power System Technology 43(8): 2961-2967.

Li, Z.W., Wu, X.L. \& Wu, X.L. 2018. Emergency Control of Synchronous Condenser to Suppress DC Continuous Commutation Failure. Automation of Electric Power Systems 42(22): 91-97.

Sha, J.B., Guo, C.Y. \& Atiq, U.R. 2019. A Quantitative Index to Evaluate the Commutation Failure Probability of LCC-HVDC with a Synchronous Condenser. Applied sciences 9(10): 925-937.

Sreejith, S., Simon, S.P. \& Selvan, M.P. 2015. Analysis of FACTS devices on Security Constrained Unit Commitment problem. International Journal of Electrical Power \& Energy Systems 66: 280-293.

Taher, M.A., Salah, K. \& Francisco, J. 2020. Optimal power flow solution incorporating a simplified UPFC model using lightning attachment procedure optimization. International Transaction on Electrical Energy Systems 30(1): 1-25.

Xiao, J., Li, X.Y. \& Feng, M. 2014. Determination of Installation Sites for Reactive Compensation Devices in Multi-Infeed AC/DC Power System. Power System Technology 38(10): 2638-2643. 
Zhao, Y., Hong, C. \& Zeng, Y.G. 2014. The Voltage Support Strength Factor (VSF) for Multi-infeed HVDC Systems and Its Application in CSG's STATCOM Allocation Scheming. Southern Power System Technology 8(4): 22-26.

Zhang, H.L., Liu, F.S. \& Li, W. 2016. Site Selection for Dynamic Reactive Power Compensation and Improvement of Recovery from Commutation Failures in Multi-infeed HVDC System. Automation of Electric Power Systems 40(5):133-138.

Zheng, K., Shen, C. \& Liu, F. 2018. Configuration Scheme of STATCOM for Mitigating Simultaneous Commutation Failure Risk of Multi-Infeed HVDC Links. Power System Technology 42(2):564-570.

Zhou, Q.Y., Zhang, Y.T. \& He, H.L. 2014. A Practical Site Selection Method for Dynamic Reactive Power Compensation in Multi-Infeed DC Power Grid. Power System Technology 38(7):1754-1757.

Zhou, S.H., Tang, F. \& Liu, D.C. 2018. Dynamic Reactive Power Compensation Configuration Method for Reducing the Risk of Commutation Failure in Multi-infeed DC System. High Voltage Engineering 44(10): 3258-3265.

Zhou, Y.Z., Wu, H. \& Song, Y.H. 2018. Analyses of static and dynamic reactive power allocation between synchronous compensators and shunt capacitors to counter commutation failures. Int International Transactions on Electrical Energy Systems 28(10): 2605-2019.

Zora, L. \& Hrvoje, P. 2019. FACTS devices and energy storage in unit commitment. International Journal of Electrical Power \& Energy Systems 104: 311-325. 